\title{
Analisa Harga Pokok Penjualan dalam Menentukan Laba pada Rumah Makan Putri Solo “Takana Jo Kampuang” Muara Bulian
}

\author{
Muryati*, Joko Susilo \\ Sekolah Tinggi Ilmu Ekonomi Graha Karya, Muara Bulian \\ "Correspondence email: dra.muryatii@gmail.com
}

\begin{abstract}
Abstrak. Penelitian ini bertujuan untuk menganalisis perhitungan harga pokok penjualan sebagai dasar menentukan harga jual produk dalam menentukan laba pada satu periode pada Rumah Makan Putri Solo "Takana Jo Kampuang" Muara Bulian. Metode yang digunakan adalah metode deskriptif dengan mengunakan pedekatan kualitatif juga dapat menggunakan penelitian untuk perhitungan harga pokok penjualan dan pengumpulan biaya yang telah di keluarkan untuk usaha makanan. Untuk Pengembalian Modal usaha usaha RM dengan kapasitas produksi yang dihasilkan. Penelitian menunjukan bahwa Rumah Makan Putri Solo "Takana Jo Kampuang" Muara Bulian mengalami kondisi keuangan yang stabil bahkan dapat mencapai hasil yang maksimal. Biaya yang telah dikeluarkan dipakai sebagai elemen perhitungan pembentukan harga pokok penjualan dan penentuan harga jual sebagai dasar dalam menentukan laba usaha. Sebaiknya pimpinan Rumah Makan Putri Solo "Takana Jo Kampuang" Muara Bulian mempertahankan dan meningkatkan usaha dengan sebaik mungkin dan berinovasi jika ingin usaha tetap bertahan sebagai rumah makan yang maju.
\end{abstract}

Kata Kunci: harga pokok penjualan; pendapatan laba

Abstract. This study aims to analyze the calculation of the cost of sales as the basis for determining the selling price of the product in determining profit in one period at The Putri Solo Restaurant "Takana Jo Kampuang" Muara Bulian. The method used is descriptive method by using qualitative attachment can also use research to calculate the cost of sales and collect costs that have been spent for the food business. For Return of Business Capital RM with the resulting production capacity. Research shows that Putri Solo Restaurant "Takana Jo Kampuang" Muara Bulian is experiencing stable financial condition and can even achieve maximum results. The cost that has been spent is used as an element of calculation of the formation of the cost of goods sold and the determination of the selling price as the basis in determining the profit of the business. The head of Putri Solo Restaurant "Takana Jo Kampuang" Muara Bulian should maintain and improve their business as best as possible and innovate if they want to keep their business as a developed restaurant.

Keywords: the cost of goods for sale; profit revenue

\section{PENDAHULUAN}

Laba suatu perusahaan merupakan salah satu faktor penentu keberhasilan perusahaan dalam menjalankan usaha. Pendapatan laba dalam perusahaan dapat digunakan sebagai tolok ukur dalam setiap kegiatan usaha untuk menilai keberhasilan yang dapat dicapai. "Pendapatan laba adalah arus masuk bruto dari manfaat ekonomi yang timbul dari aktivitas normal entitas selama satu periode, jika arus masuk tersebut mengakibatkan kenaikan ekuitas yang tidak berasal dari kontribusi penanaman modal" (Kieso, D.E, Weygandt, JJ \& Warfield, 2011). Salah satu yang mempengaruhi laba adalah harga pokok penjualan

Perusahaan dagang dan manufakture perhitungan Harga Pokok Penjualan mempunyai peranan yang sangat penting, karena setiap penjualan dan pembelian menjadikan harga pokok penjualan sebagai dasar dalam pembuatan keputusan untuk menjual atau membeli. Menurut Gill dan Chatton yang diterjemahkan oleh (Widilestariningtyas, 2012) Harga pokok penjualan (HPP) yaitu biaya pembuatan atau harga pembelian yang melekat pada produk barang jadi yang dikirim dari pemasok ke pelanggan." Dalam perhitungannya harga pokok penjualan terdapat beberapa akun merupakan persediaan awal suatu periode baru. Persediaan awal merupakan persediaan akhir dari periode sebelumnya. Persediaan akhir adalah persediaan pada akhir suatu periode atau tahun buku berjalan. Sedangkan persediaan tersedia untuk dijual adalah harga pokok persediaan dari seluruh barang yang siap untuk dijual, yang saling berhubungan. Sebelum menentukan Harga Pokok Penjualan sebaiknya kita harus mengetahui terlebih dahulu tentang harga pokok produksi yaitu pengorbanan sumber ekonomi yang diukur dalam satuan uang yang telah terjadi atau kemungkinan terjadi untuk memperoleh penghasilan (Mulyadi, 2012).

\section{Tinjauan Literatur \\ Akuntansi Biaya}

Akuntansi biaya adalah proses pencatatan, penggolongan, peringkasan, dan penyajian biaya-biaya pembuatan dan penjualan produk atau penyerahan jasa dengan cara-cara tertentu beserta penafsiran terhadap hasilnya. (Suryadi, 2013) Akuntansi biaya merupakan bagian dari akuntansi keuangan apabila akuntansi biaya ini berperan dalam memperhitungkan harga pokok produksi atau jasa yang dihasilkan dan sebagai bagian akuntansi manajemen ketika akuntansi biaya ini 
digunakan sebagai alat perencanaan, pengendalian dan pembuatan keputusan terhadap pemakaian biaya. Akuntansi biaya melengkapi manajemen dengan alat-alat yang diperlakukan untuk aktivitas-aktivitas perencanaan dan pengendalian, memperbaiki kualitas dan efisiensi, serta membuat keputusan-keputusan yang bersifat rutin maupun strategis. Akuntansi biaya mengukur dan melaporkan setiap informasi keuangan dan non keuangan yang terkait dengan biaya perolehan atau pemanfaatan sumber daya dalam suatu organisasi.

\section{Penggolongan Biaya}

Biaya digolongkan berbagai macam cara. Umumnya penggolongan biaya ini ditentukan atas dasar tujuan yang hendak dicapai perusahaan. Menurut (Widilestariningtyas, 2012) biaya digolongkan menjadi:

1. Penggolongan Biaya Menurut Objek Pengeluaran

2. Penggolongan Biaya Menurut Fungsi Pokok Dalam Perusahaan Dalam perusahaan manufaktur dikelompokkan menjadi 3 yaitu:

\section{a. Biaya Produksi}

Menurut objek pengeluarannya, secara garis besar biaya produksi dibagi menjadi tiga, yaitu: (1) biaya bahan baku; (2) biaya tenaga kerja langsung; dan (3) biaya overhead pabrik

Biaya overhead pabrik dapat digolongkan dengan tiga cara penggolongan, yaitu: (1) penggolongan biaya overhead pabrik menurut sifatnya; (2) penggolongan biaya overhead menurut perilakunya; dan (3) penggolongan biaya overhead pabrik menurut hubungannya dengan departemen

b. Biaya Pemasaran

c. Biaya Administrasi dan Umum

3. Penggolongan Biaya Menurut Hubungan Biaya Dengan Sesuatu Yang Dibiayai, yaitu Biaya dapat dikelompokkan menjadi dua golongan, yaitu: (a) biaya langsung (direct cost); dan (2) biaya tidak langsung (indirect cost)

4. Penggolongan Biaya Menurut Perilakunya Dalam Hubungannya Dengan Perubahan Volume Kegiatan Biaya dapat digolongkan menjadi: (a) biaya variable; (b) biaya semivariable; (c) biaya semifixed; dan (d) biaya tetap.

5. Penggolongan Biaya Atas Dasar Jangka Waktu Manfaatnya, yaitu atas dasar jangka waktu manfaatnya, biaya dapat dibagi menjadi dua, antara lain: (a) pengeluaran modal (capital expenditures); dan (b) pengeluaran pendapatan (revenue expenditures)

\section{Perhitungan Harga Pokok Penjualan}

Tabel 1. Perhitungan Harga Pokok Penjualan

\begin{tabular}{|l|l|l|}
\hline Perhitungan Harga Pokok Penjualan: & $\mathrm{xxx}$ & \\
Saldo awal persediaan bahan baku & $\mathrm{xxx}$ & + \\
Pembelian bahan baku & $\underline{\mathrm{xxx}}$ & - \\
Saldo akhir bahan baku & $\mathrm{xxx}$ & \\
Bahan baku yang digunakan & $\mathrm{xxx}$ & \\
& $\mathrm{xxx}$ & + \\
Bahan baku yang digunakan & $\underline{\mathrm{xxx}}$ & + \\
Biaya tenaga kerja langsung & $\mathrm{xxx}$ & \\
Biaya overhead pabrik & & \\
Total biaya produksi & $\mathrm{xxx}$ & \\
& $\mathrm{xxx}$ & + \\
Total Biaya Produksi & $\underline{\mathrm{xxx}}$ & - \\
Saldo awal persediaan barang dalam proses & $\mathrm{xxx}$ & \\
Saldo akhir persediaan barang dalam proses & $\mathrm{xxx}$ & \\
Harga pokok produksi & $\underline{\mathrm{xxx}}$ & + \\
& $\mathrm{xxx}$ & \\
Harga pokok produksi & $\underline{\mathrm{xxx}}$ & - \\
Saldo awal persediaan barang jadi & $\mathrm{xxx}$ & \\
Barang tersedia untuk dijual & \\
Saldo akhir persediaan barang jadi & \\
Harga pokok penjualan &
\end{tabular}

Sumber: (Hermawan and Masyhad, 2012)

\section{Unsur Elemen Harga Pokok Penjualan}

Untuk menentukan harga pokok penjualan ada beberapa unsur element yang penting untuk diketahui yakni persediaan barang dagangan dan harga pembelian bersih (Hermawan and Masyhad, 2012).

1. Persediaan Barang Dagangan (inventory)

Pada akun persediaan barang dibagi menjadi 4, yaitu: (a) persediaan awal; (b) pembelian; (c) persedian akhir; dan (d) persediaan tersedia untuk dijual

2. Biaya Bahan, terdiri dari: (a) Biaya angkut sebagai tambahan harga pokok bahan yang dibeli; (b) Biaya angkut tidak diperlakukan sebagai tambahan harga pokok bahan baku yang dibeli melainkan digunakan sebagai unsur biaya overhead.

Metode penentuan harga bahan dibedakan atas tiga metode, yaitu: (a) metode fifo (first in first out); (b) metode lifo (last in first out); dan (c) metode rata-rata (average)

3. Harga Pokok Pembelian, terdiri dari (a) Pembelian; (b) Retur dan potongan penjualan; (c) Potongan tunai; dan (d) Biaya angkut pembelian

\section{Perhitungan Laba}

Tabel 2. Perhitungan Laba

\begin{tabular}{|l|c|c|}
\hline Perhitungan Pendapatan Laba & & \\
Penjualan & & $\mathrm{xxx}$ \\
Retur dan Pengurangan penjualan & & $(\mathrm{xxx})$ \\
Potongan Penjualan & & $(\mathrm{xxx})$ \\
Penjualan Bersih & & $\frac{\mathrm{xxx}}{\mathrm{xxx}}$ \\
HPP & & \\
Laba Bruto & & \\
Biaya & $\mathrm{xxx}$ & \\
Beban gaji & $\mathrm{xxx}$ & \\
Beban Akm Peny, Inventaris toko & & \\
\hline
\end{tabular}




\begin{tabular}{|l|l|l|}
\hline Beban akm. Ph Invt kantor & $\mathrm{xxx}$ & \\
Beban akm. Ph Gedung & $\mathrm{xxx}$ & \\
Beban angkut penjualan & $\mathrm{xxx}$ & \\
Beban lain-lain & $\mathrm{xxx}$ & \\
Total beban usaha & & $\underline{\mathrm{xxx}}$ \\
Laba bersih sebelum pajak & & $\mathrm{xxx}$ \\
\hline
\end{tabular}

Sumber:.(Juan and Ersa 2012)

\section{Penelitian Terdahulu}

Beberapa penelitian yang berkaitan dengan penelitian ini, diantaranya:

1. (Saputra et al, 2017) mengungkapkan bahwa perhitungan harga pokok penjualan yang dilakukan oleh perusahaan sudah benar dan lebih rendah dari harga jual berpotensi dapat memperoleh keuntungan, tetapi penentuan harga jual yang dilakukan kurang tertuju karena belum dilakukannya penggolongan biaya untuk mengetahui sejumlah biaya yang akan dibebankan pada produk yang dihasilkan, juga pemakaian bahan yang berlebih berdampak pada pendapatan laba tiap periode
2. (Lasut, 2015), mengungkapkan bahwa kondisi keuangan yang stabil bahkan dapat mencapai hasil yang maksimal. Biaya yang telah dikeluarkan ini seharusnya dipakai sebagai elemen perhitungan pembentukan harga pokok produksi dan penentuan harga jual.

\section{METODE}

Penelitian ini menggunakan metode kualitatif deskriptif, yaitu penelitian yang bermaksud untuk memahami fenomena tenteng apa yang dialami oleh subyek penelitian misalnya perilaku, persepsi, motivasi, tindakan, dan lain-lain, secara bolistic dan dengan cara deskripsi dalam bentuk kata-kata dan bahasa, pada suatu konteks khusus yang alamiah dan dengan manfaat berbagai metode ilmiah. (Moloeng and Lexy 2012)

\section{HASIL DAN PEMBAHASAN}

Tabel 3. Biaya Bahan Baku Makanan Rumah Makan Putri Solo "Takana Jo Kampuang” Muara Bulian

\begin{tabular}{|c|c|c|c|c|}
\hline No & Bahan Baku & Kebutuhan & Harga Rata Rata & Total Harga/Bulan \\
\hline 1 & Beras & 60 Karung & Rp.215.000 & Rp. 12.900 .000 \\
\hline 2 & Ayam & $840 \mathrm{~kg}$ & Rp. 28.000 & Rp. 23.520 .000 \\
\hline 3 & Ikan Tongkol & $60 \mathrm{~kg}$ & Rp. 28.000 & Rp. $\quad 1.680 .000$ \\
\hline 4 & Ikan Es & $64 \mathrm{~kg}$ & Rp. 28.000 & Rp. $\quad 1.792 .000$ \\
\hline 5 & Ikan Nila & $300 \mathrm{~kg}$ & Rp. 28.000 & Rp. 8.400 .000 \\
\hline 6 & Ikan Teri & $5 \mathrm{~kg}$ & Rp. 60.000 & Rp. $\quad 300.000$ \\
\hline 7 & Ati Ampela & $510 \mathrm{Biji}$ & $\begin{array}{ll}\text { Rp. } & 1.500\end{array}$ & Rp. 1.450 .000 \\
\hline 8 & Telur & 60 piring & Rp. 45.000 & Rp. $\quad 2.700 .000$ \\
\hline 9 & Santan & $330 \mathrm{~kg}$ & Rp. 18.000 & Rp. $\quad 5.940 .000$ \\
\hline 10 & Indomie Kari & 10 dus & Rp. 92.000 & Rp. $\quad 920.000$ \\
\hline 11 & Indomie Goreng & $10 \mathrm{dus}$ & Rp. 93.000 & Rp. $\quad 930.000$ \\
\hline 12 & Soon & $60 \mathrm{bal}$ & Rp. 30.000 & Rp. $\quad 1.800 .000$ \\
\hline 13 & Jeruk Nipis & $60 \mathrm{~kg}$ & Rp. 10.000 & Rp. $\quad 600.000$ \\
\hline 14 & Kangkung & 450 ikat & Rp. $\quad 1.500$ & 675.000 \\
\hline 15 & Kacang Panjang & $60 \mathrm{~kg}$ & Rp. 10.000 & 600.000 \\
\hline 16 & Tomat & $60 \mathrm{~kg}$ & Rp. $\quad 9.000$ & 540.000 \\
\hline 17 & Tahu & Rp.15.000 & Rp. 15.000 & 450.000 \\
\hline 18 & Terong Panjang & $60 \mathrm{~kg}$ & Rp. $\quad 9.000$ & 540.000 \\
\hline 19 & Toge & $210 \mathrm{~kg}$ & Rp. 8.000 & Rp. $\quad 1.680 .000$ \\
\hline 20 & Gula Jawa & $100 \mathrm{Biji}$ & Rp. $\quad 3.500$ & Rp. $\quad 350.000$ \\
\hline 21 & Kacang Tanah & $80 \mathrm{Kg}$ & Rp. 20.000 & Rp. $\quad 1.600 .000$ \\
\hline 22 & Kol & $90 \mathrm{~kg}$ & Rp. $\quad 6.000$ & Rp. $\quad 540.000$ \\
\hline 23 & Selada & $30 \mathrm{~kg}$ & Rp. 15.000 & 450.000 \\
\hline 24 & Timun & $120 \mathrm{~kg}$ & Rp. 7.000 & Rp. $\quad 840.000$ \\
\hline 25 & Tempe & 240 & Rp. $\quad 5.000$ & Rp. 1.200 .000 \\
\hline 26 & Bayam & 150 Ikat & Rp. $\quad 1.500$ & Rp. $\quad 225.000$ \\
\hline 27 & Wortel & $15 \mathrm{~kg}$ & Rp. 10.000 & 150.000 \\
\hline 28 & Pakis & 150 Ikat & Rp. $\quad 1.500$ & Rp. $\quad 225.000$ \\
\hline 29 & Gula Pasir & 2 Sak, 100 & Rp.680.000 & Rp. $\quad 1.360 .000$ \\
\hline 30 & Minyak Goreng & 15 deligent & Rp.187.000 & Rp. $\quad 2.805 .000$ \\
\hline 31 & Nangko & $90 \mathrm{~kg}$ & Rp. 10.000 & Rp. $\quad 900.000$ \\
\hline \multicolumn{2}{|r|}{ Jumlah } & \multicolumn{3}{|r|}{ Rp. 78.062.000 } \\
\hline
\end{tabular}

Sumber: Data Primer Diolah 
Muryati dan Joko Susilo, Analisa Harga Pokok Penjualan dalam Menentukan Laba pada Rumah Makan Putri Solo "Takana Jo Kampuang” Muara Bulian

Tabel 4. Biaya Bahan Baku Minuman Rumah Makan Putri Solo "Takana Jo Kampuang” Muara Bulian

\begin{tabular}{|c|c|c|c|c|}
\hline No & Bahan Baku & Kebutuhan & Harga & Total Harga \\
\hline 1 & Teh Sariwangi & 9 kotak isi 100 & Rp. 22.000 & Rp. 198.000 \\
\hline 2 & Kopi Hitam AA & 9 kotak isi $500 \mathrm{~g}$ & Rp. $\quad 35.000$ & 315.000 \\
\hline 3 & Susu 3 SAPI & 3 Dus & Rp. 430.000 & Rp. 1.290 .000 \\
\hline 4 & Ginseng CNI & 14 Pacs & Rp. $\quad 70.000$ & Rp. $\quad 980.000$ \\
\hline 5 & Capucciono & $8 \mathrm{Pcs}$ & Rp. $\quad 90.000$ & Rp. $\quad 720.000$ \\
\hline 6 & Buah Jeruk & $250 \mathrm{Kg}$ & Rp. 15.000 & Rp. 3.750 .000 \\
\hline 7 & Buah Naga & $20 \mathrm{Kg}$ & 34.000 & Rp. $\quad 680.000$ \\
\hline 8 & Buah Mangga & $20 \mathrm{Kg}$ & 40.000 & 800.000 \\
\hline 9 & Buah Sirsak & $15 \mathrm{Kg}$ & 25.000 & 375.000 \\
\hline 10 & Buah Melon & 15 Buah & 15.000 & 225.000 \\
\hline 11 & Buah Pokat & $60 \mathrm{Kg}$ & 17.000 & Rp. 1.020 .000 \\
\hline \multirow[t]{2}{*}{12} & Teh Singa & 10 Pack & 27.000 & Rp. $\quad 220.000$ \\
\hline & & Jumlah & & Rp.10.573.000. \\
\hline
\end{tabular}

Sumber: Data Primer Diolah

Tabel 5. Jumlah Keseluruhan Biaya Bahan Baku

\begin{tabular}{lll}
\hline No. & Keterangan & Jumlah \\
\hline 1. & Biaya Bahan Baku Makanan & Rp. 78.062.000 \\
2. & Biaya Bahan Baku Minuman & Rp. 10.573.000 \\
& Jumlah & Rp. 88.635.000 \\
\hline
\end{tabular}

Sumber: Data Primer Diolah

\section{Biaya Tenaga Kerja Langsung}

Biaya tenaga kerja langsung adalah bagian dari upah atau gaji yang dapat secara khusus dan konsisten ditugaskan atau berhubungan dengan pembuatan produk, urutan pekerjaan tertentu, atau penyediaan layanan juga, kita juga dapat mengatakan hal itu adalah biaya pekerjaan yang dilakukan oleh para pekerja yang benarbenar membuat produk pada lini produksi. Tenaga kerja yang melakukan proses produksi berjumlah 2 orang. Dalam Rumah Makan Putri Solo "Takana Jo Kampuang” Muara Bulian mendapatkan gaji sebesar Rp. 17.500.000,-

\section{Biaya Overhead Pabrik}

Tabel 6. Biaya Overhead Rumah Makan Putri Solo "Takana Jo Kampuang” Muara Bulian

\begin{tabular}{|c|c|c|c|c|}
\hline No & Jenis Biaya & Kebutuhan & Harga & Biaya Produksi \\
\hline \multirow[t]{26}{*}{1} & Biaya Bahan Penolong & & & \\
\hline & a. Bumbu-Bumbu & & & Rp. 3.000 .000 \\
\hline & b. Rempah-Rempah & & & Rp. $\quad 500.000$ \\
\hline & c. Sabun Boom & 4 Dus & Rp. 60.000 & Rp. $\quad 240.000$ \\
\hline & d. Sabun Sunlight & 4 Dus & Rp. 160.000 & Rp. $\quad 640.000$ \\
\hline & e. Sabun Ekonomi & 4 Dus & Rp. $\quad 50.000$ & 200.000 \\
\hline & f. Sabun GIV & 1 Lusin & Rp. 36.000 & 36.000 \\
\hline & g. Pepsodent & 3 Pack & Rp. 40.000 & 120.000 \\
\hline & h. Kantong Plastik & & & Rp. $\quad 500.000$ \\
\hline & i. Kertas Nasi & 60 Packs & Rp. 25.000 & Rp. 1.500 .000 \\
\hline & j. $\quad$ Kotak Nasi & 4 Bal & Rp. 155.000 & Rp. $\quad 620.000$ \\
\hline & k. Kerupuk Lontong & $10 \mathrm{Bal}$ & Rp. 34.000 & 340.000 \\
\hline & 1. Saos & & & 200.000 \\
\hline & m. Kecap Bango & 2 Dus & Rp. 260.000 & 520.000 \\
\hline & n. Kecap Dua Ayam & 3 Lusin & Rp. 215.000 & 645.000 \\
\hline & o. Tisu & 1 Dus & Rp. 150.000 & 150.000 \\
\hline & p. Ajinomoto & 1 Dus & Rp. 660.000 & 660.000 \\
\hline & q. Masako & $4 \mathrm{Bal}$ & Rp. 46.000 & 184.000 \\
\hline & r. Keripik & $20 \mathrm{Kg}$ & Rp. 19.000 & 380.000 \\
\hline & s. Handwash & & & 150.000 \\
\hline & t. Pembersih lantai & & & 200.000 \\
\hline & u. Sterofom dan mika & & & Rp. $\quad 300.000$ \\
\hline & v. Gelas Jus dan pipet & & & Rp. $\quad 500.000$ \\
\hline & w. Perabotan & & & Rp. 1.500 .000 \\
\hline & x. Tutup Plastik Roll & 1 Roll & Rp. 190.000 & Rp. $\quad 190.000$ \\
\hline & & & & Rp. 12.505 .000 \\
\hline \multirow[t]{3}{*}{2} & a. Biaya Lisrik & & & Rp. 1.600 .000 \\
\hline & b. Biaya PDAM (Tanpa Pemakaian) & & & Rp. $\quad 30.000$ \\
\hline & & & & Rp. 1.630 .000 \\
\hline 3 & Biaya Tenaga Kerja Tidak Langsung & 8 Orang & & Rp. 12.000 .000 \\
\hline
\end{tabular}




\begin{tabular}{|c|c|c|c|}
\hline 4 & $\begin{array}{l}\text { Biaya Bahan Bakar } \\
\text { a. Kayu Bakar }\end{array}$ & & Rp. $\quad 600.000$ \\
\hline & b. Gas Besar & & Rp. $\quad 600.000$ \\
\hline & c. Gas Kecil & & Rp. 1.200 .000 \\
\hline & d. Bensin & Jumlah & $\begin{array}{lr}\text { Rp. } & 250.000 \\
\text { Rp. } & 2.650 .000\end{array}$ \\
\hline 5 & Wi-Fi & 1 Bulan & Rp. $\quad 350.000$ \\
\hline$\frac{5}{6}$ & Biaya BPJS Karyawan & $\begin{array}{r}8 \text { Orang } \\
\text { Jumlah Total Biaya }\end{array}$ & $\begin{array}{l}\text { Rp. } 1.600 .000 \\
\text { Rp. } 30.735 .000\end{array}$ \\
\hline
\end{tabular}

Sumber: Data Primer Diolah

\section{Perhitungan Harga Pokok Penjualan}

Tabel 7. Perhitungan Harga Pokok Penjualan

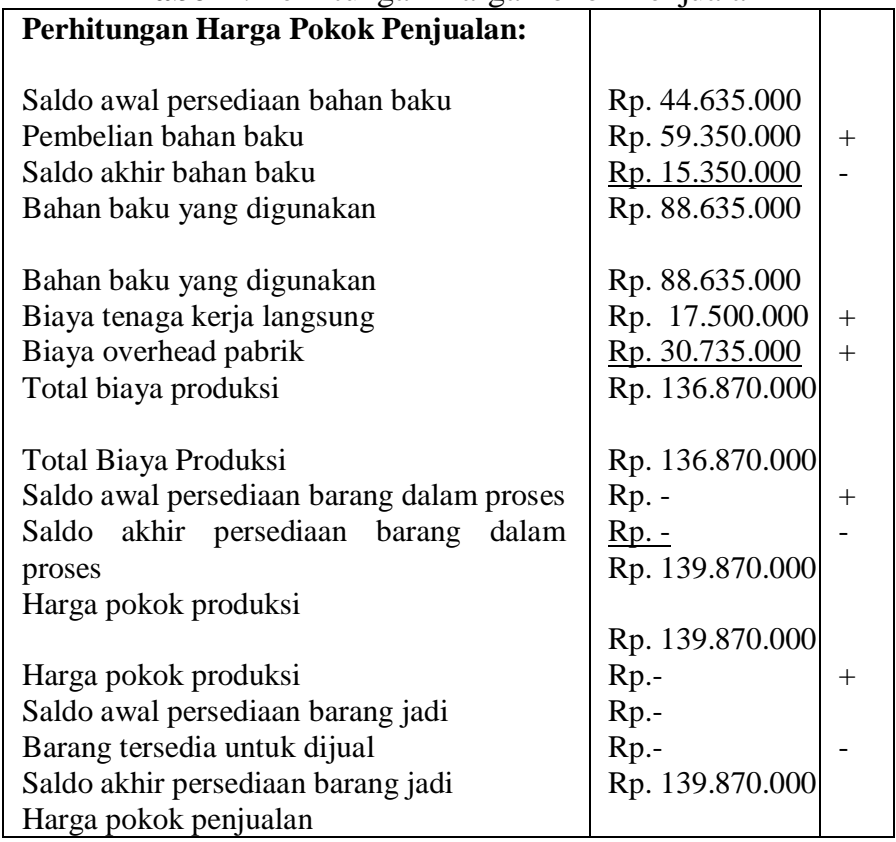

Sumber: Data Primer Diolah

\section{Perhitungan Pendapatan Laba}

Tabel 8. Perhitungan Pendapatan Laba

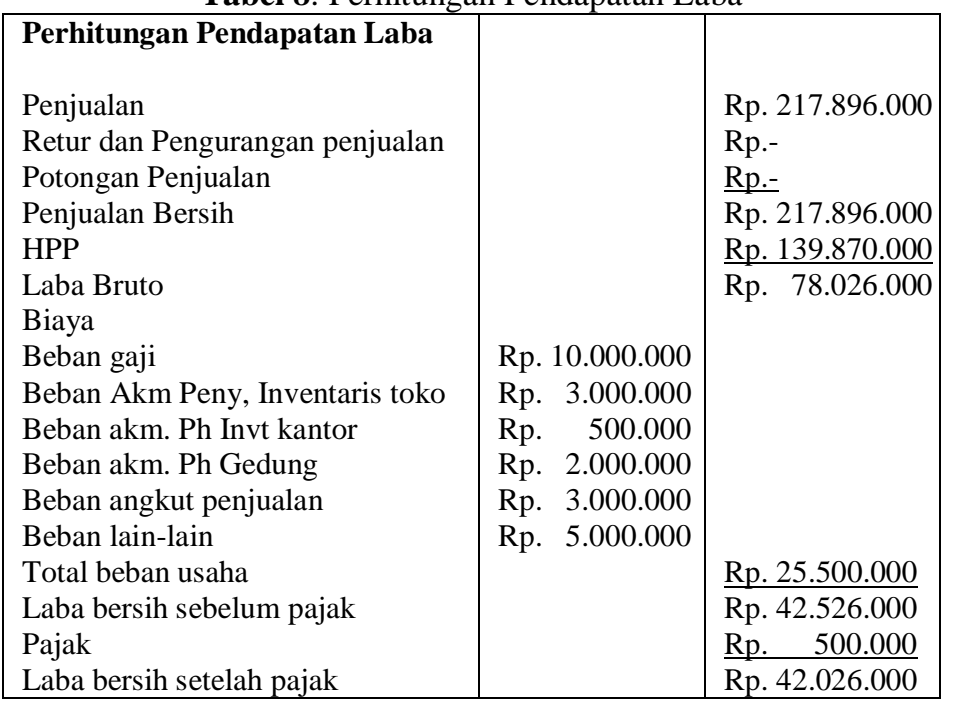

Sumber: Data Primer Diolah

\section{Pembahasan}

Pada penelitian usaha Rumah Makan Putri Solo "Takana Jo Kampuang" Muara Bulian sama seperti usaha rumah makan lain pada umumnya, orientasinya adalah untuk mencapai tujuan perusahaan yaitu menghasilkan laba yang maksimal bagi perusahaan. Untuk memenuhi hal tersebut, maka perusahaan perlu menjalankan berbagai fungsi mulai dari proses produksi hingga ke fungsi akuntansi.Seperti juga yang telah dijelaskan sebelumnya bahwa fungsi akuntansi memegang peranan penting dalam penciptaan pelaporan keuangan yang bermutu dan dapat digunakan sebagai dasar pengambilan keputusan manajemen perusahaan maupun pihak luar yang berkepentingan dengan perusahaan. Sebelum melakukan penentuan harga jual, perusahaan terlebih dahulu menentukan perencanaan karena perencanaan adalah suatu cara bertindak yang ditetapkan terlebih dahulu dalam mengambil suau keputusan dengan mempertimbangkan alternatifalternatif yang tersedia.

Rumah Makan Putri Solo "Takana Jo Kampuang" Muara Bulian membuat perencanaan dengan mengontrol biaya yang terkendalikan yaitu; biaya bahan baku, biaya tenaga kerja langsung, biaya overhead pabrik. Dalam menentukan harga poko penjualan harus mengetahui biaya produksi yang dikeluarkan berdasarkan data historis dengan penyesuaian-penyesuaian yang dibutuhkan diperiode mendatang. Dalam menyusun rencana biaya bahan baku pihak Rumah Makan Putri Solo "Takana Jo Kampuang" Muara Bulian melakukan survei dan tinjauan langsung dalam membeli dan menyediakan bahan. Untuk biaya tenaga kerja pihak Rumah Makan Putri Solo "Takana Jo Kampuang" Muara Bulian membayar biaya tenaga kerja per-hari agar pengeluaran dapat terkendali.

Pada overhead pabrik hanya beberapa hal tertentu dalam overhead pabrik yang dapat dikendalikan seperti penggunaan bahan perlengkapan dapur, biaya kebersihan, biaya listrik dan lain-lain serta tentunya biaya tersebut sudah terestimasi oleh pihak Rumah Makan. Setelah rencana diterapkan lalu dilakukan pengendalian, pihak Rumah Makan Putri Solo "Takana Jo Kampuang" Muara Bulian melalukan perhitungan 
harga pokok penjualan dalam menentukan laba setiap bulannya. Perhitungan pendapatan laba bahwa Rumah Makan Putri Solo "Takana Jo Kampuang” Muara Bulian mempunyai keuntungan yang cukup besar dan bisa menjamin kelangsungan hidup perusahaan dimasa yang akan datan.

\section{SIMPULAN}

Biaya produksi Rumah Makan Putri Solo "Takana Jo Kampuang" Muara Bulian dan analisis pada aktivitas operasi dan usaha terlihat jelas, sehingga menggambarkan kestabilan keuangan dimana pengusaha mampu mendanai sejumlah aktivitas-aktivitas rumah makan. Hal ini menjelaskan pentingnya perusahaan Rumah Makan Putri Solo "Takana Jo Kampuang" Muara Bulian untuk menyusun suatu laporan . Selain berfungsi menunjukkan laporan keuangan dalam perusahaan, penerapan laporan keuangan juga berfungsi untuk menunjukkan siap tidaknya kondisi perusahaan dimasa yang akan datang. Dari hasil penelitian diatas dapat dilihat bahwa Rumah Makan Putri Solo "Takana Jo Kampuang" Muara Bulian mengalami kondisi keuangan yang stabil bahkan dapat mencapai hasil yang maksimal.Tentunya hal ini perlu dipertahankan dan ditingkatkan oleh pemilik usaha jika ingin usaha tetap bertahan sebagai rumah makan yang maju. Rumah Makan Putri Solo "Takana Jo Kampuang” Muara Bulian memiliki kemampuan dalam mendanai setiap aktivitasaktivitas perusahaan. Capaian ini mengisyaratkan bahwa Rumah Makan Putri Solo "Takana Jo Kampuang" Muara Bulian memberikan hasil yang maksimal dan membuka peluang usaha yang baik dimasa yang akan datang.

\section{DAFTAR PUSTAKA}

Hermawan, Sigit, and Masyhad. 2012. Akuntansi Untuk Perusahaan Jasa Dan Dagang. Pertama. Yogyakarta: Graha Ilmu.

Juan, and Ersa. 2012. Standar Akuntansi Keuangan (Berbasis IFRS). Jakarta: Salemba Empat.

Kieso, D.E, Weygandt, JJ \& Warfield, TD. 2011. Intermediate Accounting Volume 1 IFRS Edition. United States of America: Wiley.

Lasut, Thelbic. 2015. "Analisis Biaya Produksi Dalam Rangka Penentuan Harga Jual Makanan Pada Rumah Makan Ragey Poppy Di Tomohon." Jurnal Riset Ekonomi, Manajemen, Bisnis Dan Akuntansi 3(1):43-51.

Moloeng, and J. Lexy. 2012. Metodologi Penelitian Kualitatif. Bandung: PT Remaja Rosdakarya Offset.

Mulyadi. 2012. Akuntansi Biaya. Yogyakarta: UPP STIM YKPN Edisi 5.

Saputra, Hermawan, Siti Rosyafah, and Widya Susanti. 2017. "Analisa Harga Pokok Penjualan Untuk Menentukan Pendapatan Laba ( Studi Kasus Rumah Makan Cepat Saji Kfc Store Pondok
Tjandra Surabaya ).” 259-71.

Suryadi. 2013. Akuntansi Biaya. Jakarta: Indeks.

Widilestariningtyas, Ony dkk. 2012. Akuntansi Biaya. Yogyakarta: Graha Ilmu. 